\title{
Carotid body tumors: A report of three cases and current literature review
}

\author{
Ayhan Muduroglu' ${ }^{1}$ and Ahmet Yuksel ${ }^{2 *}$ \\ ${ }^{1}$ Department of Cardiovascular Surgery, Bursa Yildırım Doruk Hospital, Bursa, Turkey \\ ${ }^{2}$ Department of Cardiovascular Surgery, Bursa State Hospital, Bursa, Turkey
}

\begin{abstract}
Carotid body tumors are rare, slow-growing, hypervascular neuroendocrine tumors. Although these tumors are benign neoplasm, they also have a tendency to malignant transformation. Complete surgical excision is the gold standard therapeutic modality for the treatment of carotid body tumors. Early surgical removal is recommended to prevent the development of larger and more advanced tumors, which are associated with higher morbidity and mortality. In this report, we presented three cases of carotid body tumor which were successfully treated with complete surgical excision, and reviewed the current literature. Furthermore, it was emphasized the necessity of early surgical management regardless of patient age and tumor size.
\end{abstract}

\section{Introduction}

Carotid body tumors (CBTs), also known as paragangliomas or chemodectomas, are rare neuroendocrine neoplasms which arise near the carotid bifurcation within glomus cells derived from the embryonic neural crest. The reported incidence of CBTs is $1-2$ per $100,000[1,2]$. The majority of these tumors are asymptomatic and initially noticed by inspection and palpation of neck swelling during the physical examination, or more commonly as incidental findings on radiological imaging studies. Nonetheless, the most observed symptoms are pain, dysphagia and autonomic dysfunction in symptomatic cases [3]. Although CBTs are benign lesions, they have a tendency to turn into malignant tumors in approximately $10 \%$ of all cases [4]. Thus, in order to avoid the local invasion and metastasis, early surgical excision is considered as primer curative treatment option for the treatment of CBTs. In this paper, we reported three cases of CBT which were successfully treated with complete surgical excision, and reviewed the current literature.

\section{Surgical approach}

After informing about the operation and obtaining the surgical consent forms, all three cases were taken to the operating room for primary excision under general anesthesia. The tumor mass was approached through an oblique cervical incision. The basic surgical principles included complete anatomic dissection and vascular control before the attempted tumor excision. For this purpose, all neurovascular structures were identified, and periadventitial dissections of the carotid arteries were performed. Common carotid, internal carotid and external carotid arteries were restrained using the vessel tapes before tumor resection (Figure 1). The feeding vessels supplying the tumor were initially ligated, afterwards the tumor was isolated from adjacent structures and excised (Figures $2 \mathrm{a}$ and $2 \mathrm{~b}$ ). While the masses were easily excised totally without subadventitial dissection of carotid arteries in cases of Shamblin type I and II, in case of Shamblin type III the dissection was performed along the arterial subadventitial plane to allow for complete local tumor excision, as well as preservation of carotid arteries. In all cases, the masses were excised without any neurovascular injury.

\section{Case presentations}

\section{Case 1}

A 66 year-old female patient was admitted to our outpatient clinic on account of the presence of swelling on the right cervical region. Physical examination, duplex ultrasonography and computed

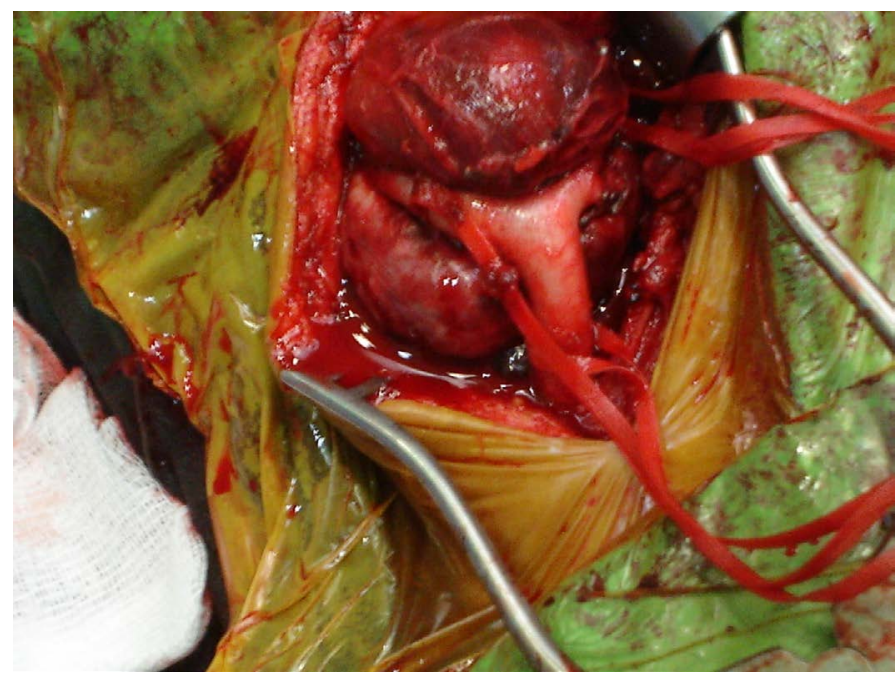

Figure 1. Intraoperative view of carotid body tumor before complete excision.

Correspondence to: Dr. Ahmet Yuksel, Department of Cardiovascular Surgery, Bursa State Hospital, Tophane Street, 16041, Bursa, Turkey, Tel: +90-505-8460753; Fax: +90-224-2132993; E-mail: ahmetyuksel1982@mynet.com

Key words: carotid body tumors, management, surgical excision

Received: August 06, 2017; Accepted: August 23, 2017; Published: August 26, 2017 


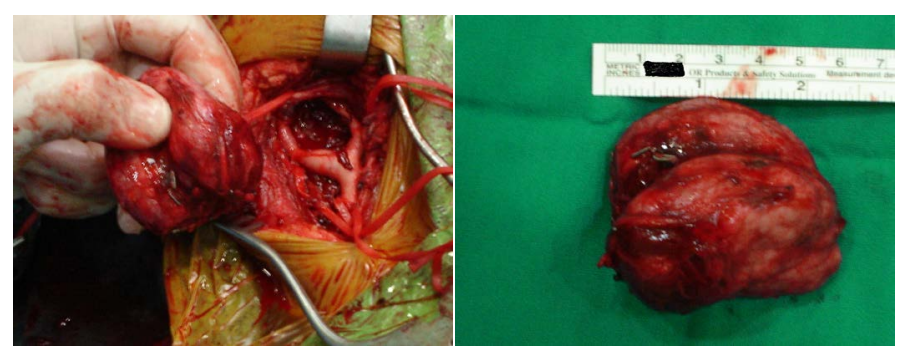

Figures 2a and 2b. Intraoperative view of carotid body tumor after complete excision.

tomography angiography revealed a mass on right carotid bifurcation measuring $15 \times 15 \times 11 \mathrm{~mm}$ that was considered as CBT. She was operated as earlier as possible after the establishment of diagnosis. Her lesion was accepted as Shamblin type I intraoperatively. She was transferred to the intensive care unit for close monitoring following the operation. On the postoperative $1^{\text {st }}$ day, the drain was removed and the patient was transferred to the clinic, afterwards she was discharged without any problems on the same day.

\section{Case 2}

A 75 year-old female patient was admitted to our outpatient clinic on account of the presence of dizziness and swelling on the right cervical region. Physical examination, duplex ultrasonography and computed tomography angiography revealed a mass on right carotid bifurcation measuring $40 \times 30 \times 24 \mathrm{~mm}$ that was considered as CBT. Additionally, vertebrobasilar insufficiency was detected according to the duplex ultrasonography findings (total volume of vertebral arteries $=166 \mathrm{~mL}$ / $\mathrm{min}$ ). She was operated as earlier as possible after the establishment of diagnosis. Her lesion was accepted as Shamblin type II intraoperatively. She was transferred to the intensive care unit for close monitoring following the operation. On the postoperative $1^{\text {st }}$ day, the drain was removed and the patient was transferred to the clinic, afterwards she was discharged without any problems on the postoperative $2^{\text {nd }}$ day.

\section{Case 3}

A 50 year-old female patient was admitted to our outpatient clinic on account of the presence of dizziness and swelling on the right cervical region. Her symptoms which were gradually increased had existed for about 15 years. Physical examination, duplex ultrasonography and computed tomography angiography revealed a mass on right carotid bifurcation measuring $75 \times 55 \times 45 \mathrm{~mm}$ that was considered as CBT. She was operated as earlier as possible after the establishment of diagnosis. Her lesion was accepted as Shamblin type III intraoperatively. She was transferred to the intensive care unit for close monitoring following the operation. On the postoperative $4^{\text {th }}$ hour, the patient was transferred to the clinic. On the postoperative $1^{\text {st }}$ day, the drain was removed, and she was discharged without any problems on the postoperative $2^{\text {nd }}$ day.

\section{Discussion}

Carotid body was firstly described by von Haller in the year 1743 [5]. It is a reddish-brown, well circumscribed, highly specialized round organ, 2-6 $\mathrm{mm}$ in size, located in the adventitia of the carotid bifurcation, supplied by the feeding vessels run primarily from the ascending pharyngeal branch of the external carotid artery, and innervated through the glossopharyngeal and vagus nerves. It functions as a chemoreceptor organ which is stimulated by acidosis, hypoxia and hypercapnea, and plays a role in the autonomous control of blood pressure, heart rate, respiration, and blood temperature in response to changes in these parameters by increasing sympathetic flow $[4,6,7]$.
CBTs are slow-growing hypervascular tumors which represent approximately $0.03 \%$ of all neoplasms. They appear more common in female gender with male-to-female ratio of 1:1.9 [8]. These tumors were reported to be malignant in $10 \%$, familial in $10 \%$, and bilateral in $10 \%$ of sporadic cases, bilaterality can reach $30 \%$ in the familial cases [4].

In the year 1971, Shamblin, et al. [9] introduced a classification system according to the relationship with the carotid arteries in order to determine the resectability of these tumors. Shamblin type I tumors are localized masses and do not involve the surrounding carotid arteries, type II tumors are adherent or partially surround the carotid arteries and thus relatively more difficult to resect, and type III tumors are large, encase the vessels and thus the most difficult type to attempt resection. According to the Shamblin classification, type III tumors are associated with more perioperative neurovascular complications and complex surgical procedure. Nonetheless, this classification system has some drawbacks since it does not reflect how deep tumor infiltrates through the wall of carotid arteries, which decides if it is possible to preserve the carotid arteries. Therefore, Luna-Ortiz, et al. [10] suggested a modification of the Shamblin classification system to make Shamblin IIIb that is clinically or histologically confirmed to infiltrate the adventitia of vessel regardless of tumor size.

Differential diagnoses of CBTs include cervical reactive lymphadenopathies, lateral cervical cysts, brachial cysts, vagal paragangliomas, thyroid nodules, carotid artery aneurysms, and parotid gland tumors. In addition to these, carotid body hyperplasia should also be remembered; it may develop on account of chronic hypoxia and is primarily described in patients living at high altitudes $[6,8]$.

CBTs have diagnostic and management difficulties since there is a lack of guidelines in the literature for their diagnosis and treatment. If a diagnosis of CBT is suspected following a detailed physical examination, the diagnosis is almost always established by radiological imaging methods such as duplex ultrasonography, computed tomography angiography, magnetic resonance angiography and digital subtraction angiography. Nowadays, ultrasonographic examination is widely used for screening because it is an easily available and noninvasive imaging modality. Moreover, in their multicenter review and meta-analysis, the Joint Vascular Research Group has recommended that duplex ultrasonography is the primary diagnostic examination for the diagnosis of CBTs [11]. Computed tomography and magnetic resonance provide to assess the size, degree and invasiveness of the tumor. Angiographic methods allow the evaluation of the vessels supplying the tumor and preoperative embolization $[8,11]$. On account of the hypervascularization and proximity to various vascular and nervous structures of these tumors, biopsy as a diagnostic method is contraindicated since it presents a risk of massive hemorrhage and dissemination, and can lead to pseudoaneurysm formation and carotid thrombosis as well $[12,13]$.

The first successful surgical removal of CBT was applied by Albert in the year 1889 [14], and Gordon-Taylor [15] defined a safe, subadventitial dissection in the year 1940. Devascularization of CBTs by ligation of feeding vessels during procedure has been a common practical surgical method since the 1980s. In the year 2008, van der Bogt, et al. [16] suggested the craniocaudal dissection technique which would minimize blood loss and thus reduce the risk of perioperative morbidity. Nowadays, surgical excision still remains the gold standard therapeutic modality for the treatment of CBTs $[8,17]$.

Radiotherapy (RT) is an alternative treatment modality which may decrease the tumor size or stop its growth. It is recommended 
for patients who cannot undergo surgery on account of extensive involvement, multiple tumors, and high operative and anesthetic risk [18]. In the study performed by Gilbo, et al. [19], which is the largest series with 156 paraganglioma cases treated with RT, the authors presented their 45-year experience and observed a decrease in size in just 5 tumors (3.2\%) and a lack of tumor growth after 5 years in $99 \%$ of the patients.

The issue of usefulness of preoperative embolization is controversial. According to some studies, the preoperative embolization procedure is beneficial since it lowers blood flow and decreases tumor size, thereby may facilitate complete tumor removal with less blood loss especially in large tumors [20-22]. On the other hand, in some other studies, the preoperative embolization was not recommended on account of not only its uselessness both also the risk of postembolization morbidity such as transient ischemic attack and even stroke by embolic particles [23,24].

Major complications regarding surgical treatment of CBTs include bleeding secondary to vascular injury, cranial nerve deficits, and perioperative stroke. The rates of complications are positive correlated with Shamblin classification $[3,6,10]$. Davila, et al. [25] reported that the rate of permanent cranial nerve injury was $5.5 \%$, and the rate of stroke was $1 \%$ stroke, without any perioperative mortality in their series consisting of 183 cases. Pacheco-Ojeda [26] has just presented the largest case series in the literature with 215 surgically excised CBTs. In his case series, the cumulative complication rate was $27.5 \%$, and these complications were mostly minor and related to cranial nerve dysfunction, with no perioperative stroke and death. An intriguing comprehensive review study which examined the complications of CBTs surgery was recently published. In this study, a total of 625 cases from 19 studies was reviewed, and the rates of transient cranial nerve injury, vascular injury, permanent cranial nerve injury, stroke and perioperative mortality were found as $31 \%, 28 \%, 17 \%, 2.5 \%$ and $0,5 \%$, respectively [27].

Regardless of patient age and tumor size, early surgical removal of CBTs is advised in order to prevent the development of larger and more advanced tumors (Shamblin class III), which are related to higher morbidity and mortality. Complete surgical excision of CBTs may be technically challenging on account of their proximity to the major norovascular structures, as well as the complex anatomy of the neck. During the surgery, all neurovascular structures should be identified in order to decrease the frequency of complications. Proximal and distal control of the carotid arteries with ligation of feeding branches is important in order to accomplish the complete tumor excision. In conclusion, surgical excision of CBTs is a very effective and safe procedure with a low rate of major neurovascular complication and mortality. Early detection and complete surgical removal of CBTs improve the outcomes.

\section{References}

1. Sevilla García MA, Llorente Pendás JL, Rodrigo Tapia JP, García Rostán G, Suárez Fente V, et al. (2007) Head and neck paragangliomas: revision of 89 cases in 73 patients. Acta Otorrinolaringol Esp 58: 94-100. [Crossref]

2. Jena A, Reddy GV, Kadiyala V, Brinda K, Patnayak R, Chowhan AK (2016) A case of large carotid body tumor: surgical challenge. Indian J Vasc Endovasc Surg 3: 96-98.

3. Dixon JL, Atkins MD, Bohannon WT, Buckley CJ, Lairmore TC (2016) Surgical management of carotid body tumors: a 15-year single institution experience employing an interdisciplinary approach. Proc (Bayl Univ Med Cent) 29: 16-20. [Crossref]

4. Albsoul NM, Alsmady MM, Al-Aardah MI, Altaher RN (2009) Carotid body paraganglioma management and outcome. Eur J Sci Res 37: 567-574.

5. Gratiot JH (1943) Carotid body tumors: collective review. Internat Abstr Surg 77: 177-186.
6. Jianu DC, Jianu SN, Motoc AG, Dan TF, Poenaru M, et al. (2016) An evaluation on multidisciplinary management of carotid body paragangliomas: a report of seven cases. Rom J Morphol Embryol 57(2 Suppl): 853-859. [Crossref]

7. Toktas F, Yümün G, Gücü A, Göncü T, Eris C, et al. (2014) Protective surgical procedures for carotid body tumors: a case series. Erciyes Med J 36: 133-135.

8. Dorobisz K, Dorobisz T, Temporale H, Zato̊̊,ski T, et al. (2016) Diagnostic and therapeutic difficulties in carotid body paragangliomas, based on clinical experience and a review of the literature. Adv Clin Exp Med 25: 1173-1177. [Crossref]

9. Shamblin WR, ReMine WH, Sheps SG, Harrison EG Jr (1971) Carotid body tumor (chemodectoma). Clinicopathologic analysis of ninety cases. Am J Surg 122: 732-739. [Crossref]

10. Luna-Ortiz K, Rascon-Ortiz M, Villavicencio-Valencia V, Herrera-Gomez A (2006) Does Shamblin's classification predict postoperative morbidity in carotid body tumors? A proposal to modify Shamblin's classification. Eur Arch Otorhinolaryngol 263: 171175. [Crossref]

11. Sajid MS, Hamilton G, Baker DM, Joint Vascular Research Group (2007) A multicenter review of carotid body tumour management. Eur J Vasc Endovasc Surg 34: 127-130. [Crossref]

12. Ferrante AM, Boscarino G, Crea MA, Minelli F, Snider F (2015) Cervical paragangliomas: single centre experience with 44 cases. Acta Otorhinolaryngol Ital 35: 88-92. [Crossref]

13. Tong Y (2012) Role of duplex ultrasound in the diagnosis and assessment of carotid body tumour: A literature review. Intractable Rare Dis Res 1: 129-133. [Crossref]

14. van der Mey AG, Jansen JC, van Baalen JM (2001) Management of carotid body tumors. Otolaryngol Clin North Am 34: 907-924. [Crossref]

15. Gordon-Taylor G (1940) On carotid tumours. Br J Surg 28: 163-172.

16. van der Bogt KE, Vrancken Peeters MP, van Baalen JM, Hamming JF (2008) Resection of carotid body tumors: results of an evolving surgical technique. Ann Surg 247: 877884. [Crossref]

17. Moore MG, Netterville JL, Mendenhall WM, Isaacson B, Nussenbaum B (2016) Head and neck paragangliomas: An update on evaluation and management. Otolaryngol Head Neck Surg 154: 597-605. [Crossref]

18. Carroll W, Stenson K, Stringer S (2004) Malignant carotid body tumor. Head Neck 26 301-306. [Crossref]

19. Gilbo P, Morris CG, Amdur RJ, Werning JW, Dziegielewski PT, et al. (2014) Radiotherapy for benign head and neck paragangliomas: a 45 -year experience. Cancer 120: 3738-3743. [Crossref]

20. Persky MS, Setton A, Niimi Y, Hartman J, Frank D, et al. (2002) Combined endovascular and surgical treatment of head and neck paragangliomas--a team approach. Head Neck 24: 423-431. [Crossref]

21. Kasper GC, Welling RE, Wladis AR, CaJacob DE, Grisham AD, et al. (2006) A multidisciplinary approach to carotid paragangliomas. Vasc Endovascular Surg 40: 467-474. [Crossref]

22. Jackson RS, Myhill JA, Padhya TA, McCaffrey JC, McCaffrey TV, et al. (2015) The effects of preoperative embolization on carotid body paraganglioma surgery: A systematic review and meta-analysis. Otolaryngol Head Neck Surg 153: 943-950. [Crossref]

23. Zeitler DM, Glick J, Har-El G (2010) Preoperative embolization in carotid body tumor surgery: is it required? Ann Otol Rhinol Laryngol 119: 279-283. [Crossref]

24. Sen I, Stephen E, Malepathi K, Agarwal S, Shyamkumar NK, et al. (2013) Neurological complications in carotid body tumors: a 6-year single-center experience. J Vasc Surg 57: 64S-8S. [Crossref]

25. Davila VJ, Chang JM, Stone WM, Fow RJ, Bower TC, et al. (2016) Current surgical management of carotid body tumors. J Vasc Surg 64: 1703-1710. [Crossref]

26. Pacheco-Ojeda LA (2017) Carotid body tumors: Surgical experience in 215 cases. $J$ Craniomaxillofac Surg. [Crossref]

27. Amato B, Serra R, Fappiano F, Rossi R, Danzi M, et al. (2015) Surgical complications of carotid body tumors surgery: a review. Int Angiol 34: 15-22. [Crossref]

Copyright: (C2017 Muduroglu A. This is an open-access article distributed under the terms of the Creative Commons Attribution License, which permits unrestricted use, distribution, and reproduction in any medium, provided the original author and source are credited. 